\title{
SYMPOSIUM
}

\section{People with disabilities in the labour market: editor's introduction}

The New Zealand journal of industrial relations has been published from Victoria University of Wellington since 1980 . This issue is the thirty-fourth, and last, to be produced by the team of Gordon Anderson, Peter Brosnan, David F. Smith and Pat Walsh, who have shared the editorial duties, for different periods, over the last 12 years. From 1992, the journal will be produced from the University of Otago.

During the last 12 years, we have endeavoured to present material which is relevant to New Zealand. And we have made an effort to encourage articles on topics which are not widely researched, or which have received inadequate treatment in overseas journals. One way that we have done this is by commissioning symposia which present a collection of papers devoted to a particular theme.

This, our last symposium, deals with a very important, but virtually neglected topic: the experience in the labour market of people with disabilities. The symposium contains 7 papers. The first, by Alison Riseborough, provides an overview of the topic. It presents some estimates of the proportion of people with disabilities, and highlights the way that they face discrimination in access to employment.

The second, and longest paper, is by Martin Sullivan. In this stimulating paper, Sullivan confronts much of the conventional wisdom concerning disability. He shows how the concept of "disability" is the result of the development of both the wage labour system and the medical profession in the nineteenth century. He argues for a more enlightened approach which sees disability as a social construction.

Verna Smith's paper introduces some economic aspects of disability. She reviews some of the issues relating to income replacement and supported employment, and looks at the policy issues involved. Her conclusion is a telling one, viz. that more research is needed.

The fourth paper is contributed by Wendi Wicks. She considers the double disadvantage of being both female and disabled in our society. She argues powerfully that the double disadvantage is more than the sum of 2 separate forms of oppression; rather that being female and disabled is a further source of disadvantage. Her paper demonstrates this clearly, and she draws appropriate lessons for policy.

Garth Bennie's paper looks at a particular policy option, Supported Employment. The philosophy of Supported Employment is at odds with the traditional sheltered workshop concept. Supported Employment is based on the belief that all people with disabilities have potential for immediate placement in real jobs alongside non-disabled workers. In his paper Bennie shows how this can work in the conventional labour market, but he also argues, as does Sullivan, that disabled people can only get a fair go if labour markets are restructured fundamentally.

Robyn Hunt's paper is also about restructuring employment. She focuses on the Public Service and examines the "merit principle". One of her many challenging conclusions is that people with disabilities enhance their organizational skills through having to manage their disability. This is just one of the aspects of disability which most employers never consider. Although Hunt's paper is written from a public sector 
perspective, the paper is highly relevant to the private sector too, and should be read by employers and unions from both sectors.

The final paper looks at the position of people with disabilities in the environment created by the Employment Contracts Act 1991. This analysis, by Philippa Bascand and Stephen Frawley, complements nicely the symposium on the Act which was published in the August issue of the journal. Bascand and Frawley's paper shows how vulnerable many people with disabilities will be in the new environment. As they argue, people with disabilities have not always had the benefit of union membership. Moreover, those who are entering the labour force for the first time, or moving out of sheltered workshops, will be quite unfamiliar with the world of work. Thus they will be disadvantaged on account of the negative stereotypes held of people with disabilities, and of their own unfamiliarity with the bargaining system. Bascand and Frawley suggest some solutions for these difficulties, but the picture they paint is not an optimistic one.

Taken as a whole, this symposium represents a refreshing challenge to all employers, unionists and academic researchers to change the way that they think about people with disabilities. It is most important that this "invisible minority" be recognized in both research on the labour market and in all policy formation.

\section{Peter Brosnan}

